\title{
MITOLOGÍAS ALIMENTARIAS COTIDIANAS Una relectura de Roland Barthes
}

\author{
LUIS ENRIQUE ALONSO BENITO \\ Universidad Autónoma de Madrid
}

\author{
PALABRAS CLAVE ADICIONALES \\ ADDITIONAL KEYWORDS \\ Roland Barthes, Alimentación, Mitologias, \\ Sociología del Consumo. \\ Roland Barthes, Food, Mythologies, Sociology \\ of Consumption.
}

RESUMEN. Este artículo es una revisión de las aportaciones del semiólogo francés Roland Barthes al estudio sociológico del consumo alimentario. En una primera parte se analizan los planteamientos de Barthes sobre el mito contemporáneo y su aplicación a la alimentación cotidiana. En la segunda parte se estudia la idea de la alimentación como forma de comunicación y sistema de signos, propia del Barthes más formalista y cercano a las tesis del estructuralismo lingüístico ortodoxo. A continuación se revisa el giro final de la obra de este autor hacia el textualismo y el hedonismo como forma de interpretación del hecho alimentario, dando entrada así a los tópicos del movimiento cultural postmoderno. Finalmente se realiza una presentación de las críticas hacia las explicaciones estructuralistas del consumo alimentario, realizadas por sociólogos como Pierre Bourdieu y Michel de Certeau, así como un balance del legado de Barthes a la construcción posible de una sociología del consumo alimentario que tenga en consideración su dimensión simbólica.

\begin{abstract}
This article is a review of the French semiologist Roland Barthes' contributions to sociological studies on food consumption. In the first part there is an analysis on Barthes' approaches on the contemporary myth and their application to the routine food consumption. In the second part it is studied the idea of food consumption as a way of communication and system of signs, which is archetypical of a more formalistic Barthes, closer this time to orthodox linguistic structuralism thesis. Subsequently, the final turn of this author's work toward textualism and hedonism as ways of interpretation of eating facts is revised, giving entrance thus to the topics of the postmodern cultural movement. Finally, it is given a presentation of the criticisms toward food consumption's structuralist explanations, carried out by sociologists as Pierre Bourdieu and Michel de Certeau, as well as a balance of Barthes' legacy to the possible construction of a food consumption sociology, which can have in consideration its symbolic dimension.
\end{abstract}

E-mail: luis.alonso@uam.es

Revista Internacional de Sociología (RIS)

Tercera Época, No 40, Enero-Abril, 2005, pp. 79-107. 


\section{RIS}

"El plato simboliza el orden que da a la necesidad del individuo particular lo que le corresponde como una parte del todo dividido, pero que tampoco le deja salir de sus fronteras"

Georg Simmel (1988:267)

"La obra de Barthes, ahora lo veo, consiste en forzar la impersonalidad del mecanismo lingüístico y cognitivo para que refleje la fisicalidad del sujeto viviente y mortal"

Italo Calvino (1998:90)

"Toda imagen de Naturaleza es una elaboración teórica. Al mismo tiempo, cada elaboración particular de Naturaleza brotará de la experiencia particular de la modernidad industrializadora del grupo concreto que es el autor colectivo de la imagen. No será nunca un relato universal, será siempre un petit récit. No será por tanto, el mundo industrial en cuanto tal que se enfrentará a naturaleza en cuanto tal; sucederá más bien que varias imágenes diferentes de Naturaleza tendrán la oportunidad de competir para su aceptación en el papel objetivo"

Agnes Heller y Ferenc Fehér (1995: 88)

\section{INTRODUCCIÓN}

A finales de los años 50 del siglo XX se produjo un portentoso encuentro entre la metodología derivada del estructuralismo lingüístico y las representaciones sociales y culturales de los alimentos; este encuentro se produjo bajo el paraguas protector de un concepto potentísimo, pero no por ello indiscutible: el de mito. Gran parte de la interpretación estructuralista del fenómeno alimentario se ha concentrado en la explicación de una mitología, dando pie a un enfoque cultural - o mejor culturalista - que se ha hecho clásico y que, en gran parte, también se ha visto mitificado en sí mismo, esto es, se ha naturalizado y sacado de su contexto de producción sociohistórica.

Pero curiosamente, además, la suerte que han corrido los diferentes análisis del mito alimentario ha sido bien distinta. Así, la versión sagrada, pesada y sistemática de la antropología estructural de Lévi-Strauss se ha convertido en un clásico contemporáneo de los estudios culturales sobre la alimentación. Sin embargo, la versión más ligera, profana y ensayística (sólo en algunos momentos) de la obra de Barthes no ha corrido igual suerte; si bien, como veremos, algunos de sus trabajos en este campo - el análisis de las representaciones simbólicas de los alimentos - se han convertido también en clásicos de la construcción de la 
semiología moderna - siendo permanentemente reeditados en varios idiomas-, resulta curioso que en los libros más completos consagrados al análisis social del hecho alimentario encontremos curiosamente o bien una ausencia casi total de referencias, o bien éstas son meramente testimoniales ${ }^{1}$; en el entorno hispanohablante, no tenemos tampoco ninguna aproximación medianamente reflexiva a su versión (mitológica) de la comida.

Lejos de ser menores o prescindibles, las fragmentarias aportaciones de Roland Barthes relacionadas con los alimentos en particular - y con el hecho alimentario en general- son un finísimo y coherente hilo de análisis y se constituyen como una aguda visión sociosemiológica de la vida cotidiana expresada en las acciones gastronómicas. Son aportaciones cuyos fundamentos han servido para desarrollar una auténtica semiótica de la alimentación contemporánea, con estudios ya bastante desarrollados y contrastados en la producción intelectual anglosajona ${ }^{2}$. Por ello, quizás cuando estamos bordeando el veinticinco aniversario de su extraña y absurda muerte, merece la pena que recuperemos la obra de Barthes para rescatarla - como dice Anne Sophie Chazaud ${ }^{3}$, en la presentación de la completa, espectacular y magnífica exposición coloquio organizada por el Centro Georges Pompidou de París en 2003- del arrollador éxito que el mismo mundo del signo (y del mito) han proyectado sobre ella, quitándole su mordiente crítica y reflexiva. $Y$ esta revisión es más necesaria, si cabe, en el tema alimentario, tan presente soterradamente a veces, y de manera luminosa en otras, en la escritura de Barthes, y cuyo sensualismo desbordante la hace, como señala la propia Chazaud, una indisoluble mezcla de inquisiciones sobre la sabiduría, los saberes y los sabores, en permanente búsqueda de sus orígenes, funciones y engaños.

Barthes abrió el campo alimentario a las posibilidades interpretativas del análisis del discurso. Esto es, sometió el hecho y las creencias alimentarias a las posibilidades de situarlas en un espacio comunicativo, donde las condiciones de percepción, pensamiento y acción dependen, no tanto de las propiedades aisladas

\footnotetext{
'En una de las contribuciones fundamentales para la sociología de la alimentación contemporánea como es la magnífica obra de Fischler (1995) no se referencia ni siquiera a Barthes. Otro gran trabajo en este terreno (también llamado a convertirse en una herramienta clave en este campo de estudio) como es el de Poulain (2002) sí hace llamadas de atención sobre la obra de Barthes, pero son más bien superficiales y en ningún caso entran en el fondo de sus argumentos. En los trabajos españoles sobre el tema, por ejemplo, la interesante introducción de Díaz Méndez y Gómez Benito (2001), tampoco se contempla la figura de este autor francés.

${ }^{2}$ Véase, por ejemplo, Leeds-Hurwitz (1993: 83-104) y el volumen recopilatorio de Counihan y Esterik (1997). En cuanto a las introducciones generales a la sociología del consumo, ver Aldridge (2003).

${ }^{3}$ Además de esta referencia de Chazaud (2003), pueden consultarse, como balances generales de la trayectoria y herencia intelectual de Barthes, los muy correctos libros de Évrard y Tenet (1994) y Culler (1987).
} 
RIS

de los objetos y los signos, como de las condiciones de verosimilitud y eficacia narrativa impuestas por un universo de reglas, normas y códigos significativos subyacentes, históricamente conformados. Códigos que adquieren un carácter generador inconsciente y naturalizador de las prácticas concretas de los actores singulares. Un sistema abstracto de reglas formales gobierna así la combinación y sustitución entre elementos en el campo simbólico alimentario -igual que en el vestido y la moda - ; desde este sistema de diferencias es posible referirse a los objetos particulares como expresiones de un modo de enunciación con sentidos referidos a una estructura ideológica que, de manera inconsciente, reproduce la totalidad de la vida social misma ${ }^{4}$.

En este artículo reconstruiremos la particular visión de Barthes de la alimentación como discurso. Una visión que evolucionó a lo largo de su obra, pero que siempre se mantuvo fiel a una férrea voluntad de desmitificación, esto es, de redescubrir en lo natural lo social, y de apertura a la aventura semiológica, es decir, al estudio de las cosas como signos, y no como signos inocentes y aislados, sino cargados de connotaciones (y, por eso, de dominaciones) y encajados en todo un sistema lingüístico que reproduce lo social desde su plano cultural. La cultura, y la cultura alimentaria en particular, deja de ser neutra, o positiva "por naturaleza", simple acumulación de acontecimientos, o memoria feliz de las sociedades: pasa a convertirse en una estructura de reconocimiento, sujeción y, sobre todo, de limitación, de ordenamiento y clasificación de las prácticas significantes para reproducir poderes invisibles incrustados en la configuración mitológica de las sociedades.

\section{LAS PRIMERAS MITOLOGÍAS ALIMENTARIAS}

En 1957 aparecía uno de los libros más atractivos y a la vez más extraños del pensamiento europeo del siglo XX: las Mitologías de Barthes. Su autor no es, por aquella época, un sólido representante de las grandes escuelas francesas o profesor en alguna de las muchas y prestigiosas universidades de París, sino un crítico literario con un oscuro pasado de enfermo pulmonar, primero, y de enseñante eventual, después, en las Universidades de Bucarest y Alejandría. Deslumbrado por Brecht y el estructuralismo lingüístico clásico (en el que había sido introducido por Greimas), becario en el CNRS que escribe por encargo, Barthes polemizaría con el siempre ejemplar Albert Camus, acabando por declararse marxista. Es autor

\footnotetext{
${ }^{4}$ Sobre las posibilidades y límites del método estructural, así como para conocer la historia del movimiento estructuralista -y el lugar ocupado por Barthes en el mismo-, es imprescindible el monumental trabajo de Dosse (2004), por fin disponible en castellano.
} 
por entonces de libros no demasiado celebrados ni conocidos: El grado cero de escritura, una recopilación de artículos aparecidos en la revista político-cultural Combat, y un libro que combina (su enorme pasión por el autor tratado), con la obra de supervivencia en estado puro: Michelet par lui-même.

En esto aparece Mitologias, un libro casi seccionado en dos. La primera parte es un conjunto de cincuenta y tres estampas de la vida cotidiana francesa de su tiempo, la mayoría de ellas aparecidas mensualmente entre 1954 y 1956 en la revista Lettres nouvelles en su sección "Petite mythologies du mois". La segunda parte del libro es una profunda reflexión sobre "El mito hoy", donde se aborda el mito como habla, como sistema semiológico secundario y, a partir de ahí, se trata de crear una semiología general de la cultura y la vida cotidiana, mucho más allá del primer proyecto semiológico (lingüístico) de Saussure. El autor es inmediatamente atacado por su ausencia de fundamento por un buen número de lingüistas ortodoxos, que se negaban desde este primer instante a acompañar, en este tan inseguro viaje, al en aquella época poco reconocido Barthes 5 .

En las Mitologías hay, desde el principio, un proyecto de desnaturalización, de romper el halo de lo normal y natural que impone el mito, proyectando sobre los pequeños hechos mitificados de la vida cotidiana su mirada casi mineral. Así, entre la lucha libre y los detergentes, el strip-tease y el nuevo Citroën, el cerebro de Einstein y el plástico, aparecen tres pequeñas mitologías alimentarias: "El vino y la leche", "El filete y las patatas fritas" y "La cocina ornamental". En "El vino y la leche", Barthes despliega una fascinante interpretación de la mitología del vino como tótem de la nación francesa y sobrepasa, con mucho, el arranque psicoanalítico que toma de Bachelard" (jugo de la tierra y del sol, líquido "no húmedo", sino seco y por lo tanto contrario al agua). Barthes da al vino francés la característica de mito vivaz y acomodaticio: sirve como transformador alquímico de los humores, de los estados de ánimo, de los silencios, de la inspiración. Es una mitología basada en la sangre, la vida y la eucaristía. Mito plástico y fraternal

\footnotetext{
${ }^{5}$ Las Mitologias de Barthes (edición española de 1980) conocen un inaudito renacer en la literatura de las ciencias sociales francesas, como lo demuestran un par de buenos análisis críticos del libro, de estilo muy diferente, como son el de Cobast (2002) y el de François-Denève (2002). En cuanto a la reacción crítica y descalificadora de la lingüistica académica hacia la obra de Barthes, el gran abanderado y defensor de una semiología restringida es, por supuesto, Mounin (1972 y 1987, entre muchos más). Pero a pesar de Mounin, las Mitologias se han convertido en referencia para cualquier introducción a la semiología que se precie: véanse así los muy conocidos libros de Guiroud (1972) y Martinet (1988).

${ }^{6}$ Es bien conocida la influencia de Bachelard sobre todo el movimiento estructuralista. Sus ideas sobre la negación del sentido común distorsionador, y sobre el racionalismo aplicado como negación de las apariencias y como psicoanálisis que busca los símbolos primitivos en los materiales que se intercambian socialmente, son también evidentes en este primer Barthes, que lo cita respetuosamente, sobre todo sus trabajos de los años cuarenta sobre la "imaginación de la materia" (véase Bachelard (1978) y, como revisión totalizante de todos los aspectos de este autor, Wunenburger (2003)).
} 
RIS

por excelencia - lo mismo separa (vinos distinguidos) que une (el vino popular)-, en Francia toma la forma de decorado universal de la identidad nacional: no es una bebida instrumental (para provocar borracheras fáciles o placenteras como el whisky en ese tiempo), sino la expresión total de un pueblo que por eso todo lo comprende, todo lo perdona, todo lo disculpa: el vino es la falsa armonía de la razón de Estado. Como elemento contrario al vino ya no aparece sólo el agua (que sigue teniendo el aura mítica de la pureza), sino la leche, convertida sociológicamente en elemento cosmético (término y concepto que resuena constantemente en toda la obra de Barthes). La leche liga, nutre y restaura, frente al mito quirúrgico, transmutador y engendrador del vino. El de la leche es un mito parsifaliano: es la fuerza de la inocencia, origen de lo que hoy llamaríamos alimentos funcionales y, por lo tanto, obsesivamente encajados en la salud antes que en el placer, placer que para Barthes va a ser la característica última del alimento mismo. Triángulo de mitología cotidiana (vino, leche, agua) que, sin embargo, dice Barthes, no es inocente, comprime la fuerza de la sociedad sobre la alimentación del individuo, pero también, en el caso del vino, oculta los obscuros orígenes de la producción del vino (explotación y expropiación del capitalismo francés del mito en su propio provecho).

Inmediatamente aparece otro mito sanguíneo como el vino: el bistec, corazón de carne, casi-crudo, ligado a su relación directa con la fuerza taurina, la animalidad, la lucha y la victoria que supone hincarle el diente. Relación directa con la vida $\mathrm{y}$, por ello, con la muerte, en un estado casi crudo o incluso crudo del todo (en la moda del steak tártaro), sustancias sanguíneas, blandas o ablandadas, vitalizante. Pero el bistec es también un mito nacional, plástico y reconciliatorio. Carne, dice Barthes, más nacionalizada que socializada, que se representa tanto en la imagen de la alta calidad (el ancho y esponjoso corte de carne de la confortable mesa burguesa), como en la de la comida popular (el rápido y familiar filete con patatas), pasando por el bocado expeditivo, rápido y alimenticio de la comida laboral o del socorrido plato del soltero. Todas las combinaciones y presentaciones del bistec lo emparentan con la naturalidad de la vida francesa normalizada, frente a lo exótico o lo extraño. Símbolo del tesoro patriótico de la dulce Francia frente a lo excesivamente moderno, inexplorado y peligroso. Las patatas fritas lo unen igualmente con la tierra, completan el ritual de la etnia reencontrada: todo es "francesidad" hecha alimento.

Frente a esta mitología sanguínea y primaria, aparece la mucho más elaborada y sofisticada de lo que Barthes llama "la cocina ornamental", refiriéndose a las hermosas fotografias polícromas de las recetas publicadas por la revista Elle. Dice Barthes que, en esta revista, crisol de la mitología modernizante de la Francia de los años cincuenta, la cocina es exclusivamente visual, y su categoría es la cobertura: las salsas, gelatinas y fondants reducen y ocultan la naturaleza primaria del alimento; la distinción es el disfraz que separa al alimento de su origen natural y regional y lo convierte en ornamento de la vida burguesa. La ornamentación mata a la auténtica naturaleza ( $\mathrm{y}$ a la auténtica cultura), así como la sustituye por falsas 
naturalezas y culturas (muertas). Las ideas en la ornamentación de este tipo de cocina (y de publicación) se limita a la guarnición, es decir a aquello que difumina lo fundamental del problema alimentario, empezando por el problema alimentario mismo (tener dinero para comprar comida). Inaccesible para muy amplios sectores de lectores populares de la revista, la cocina ornamental está sostenida y sostiene una economía mítica (cocina de ensueño realizada sólo en la mirada y, por ello, en la envidia). Por ello, la cocina de Elle es absolutamente inasequible, irrealizable, y con eso el poder burgués se refuerza, gana en eficacia mágica y simbólica. Una revista de referencia burguesa como L'Express plantea en su sección de cocina recetas para hacer; una revista genérica como Elle plantea recetas para desear (desear no tanto comer como poder comer como los burgueses), deseo que refuerza todos los poderes.

En su libro El grado cero de escritura Barthes acababa diagnosticando que no hay nada natural en la literatura naturalista, y que la llamada claridad no es más que el respeto a la lógica burguesa: por lo tanto, el realismo literario no es que describa ninguna realidad, sino que combina una serie de signos predeterminados tomados como realistas, según un código también predeterminado que es igualmente considerado realista. De la lectura de las Mitologías se podría desprender que no hay nada de natural en la alimentación natural. El mito alimentario convierte lo socialmente aceptable, lo moralmente deseable y lo estéticamente convencional, en natural, pero esto no es otra cosa que reproducir un código relacional y una construcción simbólica que fijan los poderes sociales. El mito en Barthes es así un habla y un sistema semiológico secundario. Aceptando por aquella época casi de manera absoluta los principios saussurianos de la lingüística estructural - separación entre lengua/habla, significado/significante, sintagma/paradigma; arbitrariedad del signo, etc.- , nuestro autor se empeña en ampliar realmente el campo de la semiología propugnada por Saussure, hasta construir una disciplina general de la significación muy por encima de los lenguajes naturales. Así, el mito se convierte en el arco del puente de este recorrido: el mito es un metalenguaje, se construye sobre una relación de significación entre significante y significado ya existente, para encajarse luego como un signo secundario, cuya referencia es ya una estructura lingüística y cultural puramente autorreferente. El mito, pues, no tiene sustancia de realidad alguna, sólo forma y relación con un sistema de conocimiento donde se actúa por oposición y diferencia; es un habla despolitizada en el sentido profundo del término, es decir, un sistema comunicativo que ha roto sus relaciones con la capacidad de los hombres de producir su mundo, para instaurar el poder de la reproducción de los ídolos 7 .

\footnotetext{
7 Para una revisión completa del concepto de mito en las ciencias humanas, incluyendo la presentación a Barthes, véase Jessi (1976). Por otra parte, pocas veces se encontrará una síntesis tan apretada sobre las relaciones entre mito y sistema de significación como en las últimas páginas de las Mitologias, que se recogen aquí en estos párrafos. El encuentro entre el mito y la cultura de masas está magníficamente tratado en el clásico de Eco (1995).
} 


\section{RIS}

Según Barthes, el mito, por tanto, funciona: como vacuna -inmuniza el imaginario colectivo por una pequeña vacunación del mal reconocido, es una pequeña verdad en una gran mentira-; como privación de la historia -es el objetivo del mito, evaporar la historia: todo lo inquietante desaparece y se redondea en extremos, la libertad absoluta o el determinismo absoluto-; como identificación -la proyección de la propia identidad sobre todo, sin posible aceptación del otro o de lo otro; el mito burgués esculpe la sociedad a su imagen y semejanza-; como tautología - la realidad es así porque es así, y el mito no tiene otro discurso que ése, lo que existe es lo natural-; como ninismo - término que Barthes utiliza para designar una figura de no elección: el mito, una vez que da por sentada una realidad, deja fuera cualquier otra opción; es esto, ni lo uno, ni lo otro, ni ésto, ni aquél, ni derecha, ni izquierda, etc.--; como cuantificación de la cualidad - el mito se funde en la medida, en la economía de la inteligencia; actúa por la asociación de una cantidad inducida (lo más, el mejor, lo mayor o sus simétricas: lo menos, el peor, el más pequeño); y como verificación -el mito tiende al proverbio, a la máxima, todo lo que acontece da la razón al orden simbólico preestablecido. Todas estas funciones operan en el mito alimentario, una retórica que guía nuestras prácticas como doxa o sentido común culinario: comemos signos, cocinamos mitos, atribuimos efectos naturales a un sistema de creencias exclusivamente social.

Las diferencias sobre el planteamiento relativo al mito - y específicamente sobre el mito alimentario- entre Barthes y Lévi-Strauss son importantes, a pesar de la raíz común, convencionalmente considerada como estructuralista ${ }^{8}$. Para ambos, el mito tiene una autonomía sobre el sujeto, se funda sobre signos arbitrarios. Los mitos piensan a los hombres y se piensan entre sí; clasifican y ajustan cognitivamente. El alimento, al entrar en esta estructura mítica, es pensado antes que comido, y por lo tanto no somos tanto lo que comemos como lo que pensamos y somos pensados, utilizados y activados por las mitologías alimentarias (comemos lo que queremos creer). Pero superando este primer nivel de estructura - de regla mental inconsciente, combinatoria y recurrente-, la versión del mito alimentario en Lévi-Strauss es etnográfica, monumental (en su inmensa clasificación de los mitos de los indios americanos), con pretensión de

\footnotetext{
${ }^{8}$ El lugar de Barthes y Lévi-Strauss en los estudios contemporáneos y análisis sobre la comunicación está bien registrado en Mattelart y Mattelart (1997). Es bien evidente el respeto de Barthes a la obra de Lévi-Strauss (las citas, referencias e incluso recensiones de los textos del antropólogo se encuentran diseminadas en toda su obra). Sin embargo, la distancia y displicencia de Lévi-Strauss sobre el trabajo de Barthes está bien recogido incluso de manera biográfica: para ello sólo hace falta revisar el imprescindible trabajo sobre Barthes de Calvet (1992), que es mucho más que un relato interesante de la vida del autor (lástima que la traducción no esté a la altura de las circunstancias).
} 
universalidad y sin carácter práctico (el mito se vincula con el mito mismo y otros mitos más allá de la historia y el lugar). Su triángulo culinario (lo crudo, lo cocido, lo podrido) se convierte en un triángulo sémico de transformaciones sucesivas y composiciones según la doble oposición cultura/naturaleza y elaborado/no elaborado. Sus "mito-lógicas" sobre los orígenes de las maneras en la mesa -como lógica de las proporciones-, o la de la miel y las cenizas como oposición entre el peligro de la seducción y la búsqueda de lo sobrenatural en secuencias ritualizadas, son todas ellas ejemplos potentísimos de una ordenación arquetípica del caos del mundo por unas lógicas míticas que funcionan metafóricamente en el inconsciente humano según reglas estrictamente lingüísticas (atemporales, de selección y composición) ${ }^{9}$.

En Barthes, sin embargo, el mito alimentario es cotidiano, práctico, nacional, burgués, histórico; lo que toma del marxismo no es, como Lévi-Strauss, su capacidad analítica abstracta, sino su desmitificación concreta. El mito alimentario de Barthes no se fragua, por tanto, en el inconsciente humano, sino en el preconsciente de las culturas nacionales: en la reproducción práctica de lo que siendo histórico ha sido sacado de la historia, de lo que siendo cultural ha sido convertido en natural y de lo que, expresando desigualdad y diferencia, ha sido convertido en armónico y general. El mito alimentario es aquí, mucho más relativo, ligero y profano. En síntesis, es cotidiano: interactúa en el mundo de la vida de las relaciones intersubjetivas, conformándolas según un sistema cultural preestablecido, y si bien lo "bueno para comer" ha sido así porque, como decía Lévi-Strauss, previamente ha sido bueno para pensar, en Barthes este pensar es concreto, ideológico, producto de la historia y encuadrado en una sociedad. "Somos lo que creemos", "comemos lo que creemos", pero en la creencia y en la naturaleza se han ocultado los sistemas de producción del sentido según intereses, la expropiación y el dominio burgués sobre el relato mismo de la modernidad.

\section{EL SISTEMA DE LOS ALIMENTOS. EI Barthes formalista}

Desde finales de los años 50 y a lo largo de los años 60, Barthes realiza sus trabajos más formalistas, e incluso más rígidos desde el punto de vista metodológico. Su empeño semiológico le lleva a una depuración de los fundamentos teóricos de su análisis por la vía de las sucesivas reformulaciones de los conceptos fundacionales (lengua/habla, significante/significado, connotación/denotación, sintagma/sistema, etc.), y la aplicación de estos constructos analíticos a diferentes

\footnotetext{
${ }^{9}$ Los cuatro impresionantes volúmenes de las Mitologias de Lévi-Strauss (1968, 1971, 1974 y 1981) están construidos a partir de mitos alimentarios. La exposición más sintética del concepto de mito en este autor se encuentra en Lévi-Strauss (1987).
} 
RIS

REVISTA INTERNACIONAL DE SOCIOLOGIA

№ 40, ENERO-ABRIL, 2005

LUIS ENRIOUE ALONSO BENITO

campos temáticos (como el vestido, el alimento, el automóvil y el mobiliario). Es un período de limitada estabilización académica - jefe de estudios y director de investigación, sucesivamente, en la entonces École Pratique des Hautes Édudes gracias a un equipo formado por Georges Friedman para el estudio de los fenómenos comunicativos-, con el permanente deber no realizado de una tesis doctoral, definitivamente no presentada. Nunca demasiado cómodo en la jerarquía universitaria, todos los fantasmas se concentran cuando las voces más tradicionales de los estudios filológicos franceses (Raymond Picard), debidamente ampliadas periodísticamente por el eterno y poco sutil ultraconservador JeanFrançois Revel, acaban sentenciando a la Nueva crítica que practicaba Barthes como una simple impostura ${ }^{10}$. En ese tiempo, nuestro autor se sentía obligado a demostrar su sistematicidad, su rigor, la pertinencia de su método y la pulcritud de su trabajo; así, producirá alguno de los monumentos del estructuralismo francés más correoso, como es su libro El sistema de la moda, aparecido pocos meses antes de los acontecimientos de Mayo del 68.

En ese período, las referencias a la alimentación en la obra de Barthes eran permanentes, empezando por un artículo de 1961 en la revista Annales. Economies, Sociétés, Civilisations, una de las publicaciones centrales de la historiografía francesa del siglo XX, y en la que ya había publicado algún artículo (sobre el vestido fundamentalmente). En principio, la revista Annales era, como se sabe, el foro más alejado posible de la entonces llamada "revolución estructuralista"; sin embargo, su preocupación por los procesos que configuran históricamente la vida cotidiana hacían coherente el encargo a un estructuralista tan heterodoxo como Barthes de un trabajo, en un número monográfico sobre la historia de la alimentación. El artículo en cuestión se titulaba "Por una psicosociología de la alimentación contemporánea" 11 - todavía no aparece la palabra semiología directamente en sus títulos; habrá que esperar a 1964 cuando se publican sus Elementos de semiología, centro teórico de ese período y con una ilustración alimentaria también interesante- y es un buen ejemplo del programa de investigación que Barthes desarrollaba en la École Pratique, y de la maduración metodológica de su propio enfoque analítico. Lo primero que llama la atención de este trabajo es

\footnotetext{
${ }^{10} \mathrm{De}$ aquella amarga experiencia para Barthes surge un libro como Critique et vérite, todo un manifiesto contra las críticas descriptivistas, naturalistas y filológicas. Surgiendo sobre las divergencias en la interpretación de un autor (Racine), ha llegado a convertirse en un clásico de la llamada nueva critica (primero estructuralista y luego postestructuralista), donde se destierra cualquier pretensión de verdad como concepto absoluto y positivo (ver Barthes, 1981).

${ }^{11}$ Este artículo (Barthes, 1961: 977-986) es el colofón de una serie de artículos en Annales, donde Roland Barthes anticipa lo que serán el centro de sus intereses teóricos de la etapa de madurez. Posteriormente, colaborará con otras revistas mucho más cercanas a la escuela estructuralista, como Arguments, Communications, o Tel Quel.
} 
que ya no disecciona mitos alimentarios, sino que se enfrenta con la alimentación como sistema, es decir, como un lenguaje en su conjunto. Los elementos del hecho alimentario, los ritos de hospitalidad, los menús de la vida cotidiana, las costumbres culinarias dependientes de los grupos sociales, las comidas festivas, etc., no son tratados sólo como objetos de consumo o prácticas rutinarias, sino que constituyen un verdadero sistema de signos, es decir, forman una unidad funcional en una estructura de comunicación. Desde este punto de vista, la alimentación es una necesidad, pero una necesidad imposible literalmente de realizar fuera de una estructura social comunicativa. Aquí el término "comunicación" es también total y textual, y para Barthes está tomado en un sentido fuerte: es una estructura compuesta por elementos (simbólicos) interdependientes, que sobrepasa la consciencia de los actores en presencia o la simple palabra o diálogo verbal. Es un sistema instituido de palabras, objetos, alimentos y gestos, que crea una gramática - y una poética- compleja y completa. Los discursos pedagógicos sobre la alimentación, casi siempre inútiles, olvidan este carácter total y mixto (comunicativo, material) y tratan - casi siempre ingenuamente- de racionalizar (técnicamente) lo que tiene un sentido simbólico y social y, por lo tanto, tiende a componerse como un sistema total (ritual o antirritual).

Barthes argumentaba que la trivialización y futilización del hecho alimentario explica que las ciencias sociales se hayan dedicado poco a este asunto; sólo las ciencias naturales lo han hecho dignificando el objeto en su forma compositiva/ analítica. Ello ha impedido observar el auténtico carácter de lenguaje que tiene la comida, pues no deja de ser un conjunto de elementos que son como palabras (ingredientes) que se organizan según reglas gramaticales (recetas, transformaciones, formación de platos, cocinados, etc.), sintácticas (orden de ingestión, composición de menús, etc.) y retóricas (lo que se puede decir y no decir de la comida que se come, y lo que se dice con la comida). Pero la analogía con el lenguaje no sólo opera en un plano sintagmático: también se establece en el ámbito pragmático, en los efectos del sentido que transmite. Así, la alimentación, como el lenguaje, expresa la tradición y la identidad de los grupos sociales, pero también su posibilidad de intercambio (intra y extragrupo; intra e interculturas). La comida abre y cierra las culturas: su penetración puntual, ocasional o parcial puede ser rápida, pero el cambio alimentario en su conjunto es lentísimo. Los préstamos alimentarios, como los préstamos lingüísticos, acaban modificando sólo relativamente - pero efectivamente - el sistema sociocultural que lo enmarca cotidianamente, lo que le da un sentido total a la vez que complejo.

Según Barthes, por tanto, existe una economía simbólica de las posibilidades alimentarias (atracciones y repulsiones, combinaciones y elecciones legítimas). La comida nos remite a una necesidad (o a un placer) inicial; constituye una realidad inmediata. Sin embargo, toda sustancia, técnica o uso sólo tiene sentido si se combina dentro de un sistema de diferencias significativas, cuya coherencia no viene de una lógica razonada o positiva, sino de una falta de esa lógica (una 
RIS

REVISTA INTERNACIONAL DE SOCIOLOGIA

№ 40, ENERO-ABRIL, 2005

LUIS ENRIQUE ALONSO BENITO

lógica negativa), una lógica histórica y contextual. Los hombres no se alimentan (sólo) de nutrientes naturales ni de principios dietéticos puros, sean estos sagrados o profanos ${ }^{12}$, sino de alimentos culturizados simbólicamente, construidos en referencia a una historia común. Las leyes de la comestibilidad y la comensalidad son leyes de compatibilidad, conveniencia, ajuste y expresión de identidad de cada área cultural; los alimentos y los manjares se ordenan en cada región de acuerdo con un código detallado de valores, reglas y símbolos en torno al cual se organiza el modelo de un área cultural en un período determinado. Esto hace, por ejemplo, que lo que es imposible en Francia, como mezclar los sabores dulces y salados rotundos en un plato principal, sea considerado elemental en la cocina anglosajona; o que las texturas crujientes sean centrales en los desayunos norteamericanos, frente a las texturas suaves francesas. Los códigos alimentarios son así potentes; son estructuras míticas completas que encajan en culturas concretas y acaban dando verosimilitud y legitimidad a los alimentos tomados en su dimensión más física y organoléctica.

A mediados de los años sesenta, Barthes se encuentra en el momento más formalista de su producción. Tanto en algunos artículos de esa época, como en los trabajos de investigación de su grupo de la École Pratique ${ }^{13} \mathrm{y}$, sobre todo, en el núcleo mismo de su opúsculo Elementos de semiología, podemos encontrar una referencia sistemática a la alimentación, junto con el vestido, el mobiliario y la arquitectura - entre otras - como estructuras significantes que se tienen que decodificar. En un pequeño artículo de 1964, titulado muy gráficamente "La cocina del sentido", encontramos referencias alimentarias, y allí se nos dice que todos los signos (y el signo alimentario fundamentalmente) están constituidos por diferencias. Por lo tanto, hay que leerlos, o sea, atribuirles un sentido (lo que producen) y una significación (lo que dicen), y esto se hace no sólo como un proceso de extracción de información literal de esos signos, sino como una lectura de su vida social (sus valores sociales, morales e ideológicos). El signo,

\footnotetext{
${ }^{12}$ En algunos momentos de ese período, la obra de Barthes es capaz de alejarse del estructuralismo más rígido y anticipar un enfoque mucho más contextualista y cognitivo de la alimentación. Es predecesor del que luego será desarrollado en autores como Douglas (1998: 152-166) o Goody (1995), donde se cuestionan las clasificaciones alimentarias abstractas.

${ }^{13}$ Afortunadamente, disponemos hoy de una edición ampliada de El sistema de la moda (el libro más formalista y académico de Barthes, la tesis doctoral que nunca llegó a ser tal, y que acaba siendo un exhaustivo análisis estructural de las revistas de moda), con los artículos y documentos de trabajo preparatorios de las actividades de su seminario en la École; actividades que comprendían un Inventario de los sistemas contemporáneos de significación (sistemas de objetos, vestido, alimento, vivienda) y donde se estaban formando autores de tanta relevancia posterior como Jean Baudrillard, Luc Boltanski o Jean-Claude Milner (véase Barthes, 2004: 409 y ss.). De las muchas ediciones ya en castellano de los "Elementos de semiología", la primera se encuentra en Barthes (1971). El artículo "La cocina del sentido" está compilado en Barthes (1990: 223-227).
} 
pues, no sólo denota, sino connota: la producción simbólica de las sociedades modernas es cada vez más ingente, por lo que las connotaciones son más complejas y los alimentos ya no sólo son buenos para comer, o buenos para pensar, sino buenos para leer. Tienen que connotar valores positivos encajados en un sistema semiológico para tener cierta eficacia simbólica. Si en la lingüística estricta -de corte saussuriano- el signo es arbitrario, en la semiología de Barthes el signo es motivado, opera por cadenas de connotación y analogía: el sentido es articulación de elementos que cristalizan en un contexto social determinado.

En los Elementos de semiología también se utiliza la alimentación como un ejemplo completo de sistema de significación. El lenguaje de los alimentos está constituido por: a) reglas de exclusión/inclusión (tabúes alimentarios); b) reglas de oposición significativa (salado/dulce, caliente/frío, nacional/exótico); c) reglas de asociación, sea simultáneas (un plato) o sucesivas (un menú, una dieta), y d) los protocolos de uso, que funcionan como una retórica de la alimentación. El habla alimentaria es, así, extremadamente rica, porque recoge todas las variaciones personales de preparación o asociación. De hecho, Barthes llega a comparar la práctica culinaria de una familia con un ideolecto ${ }^{14}$. Por lo tanto, todo menú está constituido con referencia a una estructura (nacional o regional y social en todo caso), pero esta referencia queda actualizada y rellenada de manera diferente según los días y los usuarios. La relación entre el lenguaje y el habla alimentarios sería, por tanto, muy semejante a la de los procesos lingüísticos puros: somos sujetos sujetados por un lenguaje alimentario que le da sentido a nuestras acciones, que no dejan de ser ajustes secundarios y combinatorias de un idioma inconsciente y todopoderoso que es el código general determinante. Barthes, además, introduce aquí un concepto tomado de Hjelmslev como es el $u s o^{15}$, asegura que el lenguaje alimentario se produce por una sedimentación de los procesos, por un uso social que consagra las combinaciones formales legítimas y que, a la vez, permite las innovaciones individuales, con menos peso, dice Barthes, de los grupos de decisión que en la moda textil (hoy esta afirmación había que relativizarla y cuestionarla). El código alimentario se constituye a partir de un uso, en gran medida colectivo y de un habla puramente individual. Nadie come inocentemente; toda práctica alimenticia es un discurso que expresa un sistema de selección (unidades elegidas)

\footnotetext{
${ }^{14}$ La noción de ideolecto (ver Greimas y Courtés, 1982: 214) viene a indicar la actividad productora y/o lectora de significaciones, propia de un actor en un universo semántico dado. Estas variaciones individuales son, en sí mismas, interindividuales, pues la actividad creadora siempre tiene que ser homologada en un universo semántico colectivo.

${ }^{15}$ Es sabido que Hjelmslev introduce en la dicotomía saussuriana lengua/habla la noción de usos lingüisticos, como conjunto de hábitos lingüísticos de una sociedad dada que se diferencia del esquema lógico de la lengua y de las variaciones estilísticas individuales del habla (véase Hjelmslev, 1974: 68-73).
} 
RIS

REVISTA INTERNACIONAL DE SOCIOLOGÍ

№ 40, ENERO-ABRIL, 2005

LUIS ENRIQUE ALONSO BENITO

y un sistema de composición (combinación y preparación de estas unidades), reproduciendo (interesadamente) los códigos de la cultura y la sociedad de referencia.

En esa época, los contactos de Barthes con el mundo de la producción publicitaria eran intensos. El deslumbramiento de algunos ejecutivos de las grandes agencias francesas (como el interesante Georges Peninou) por la obra de nuestro autor acabaría generando un buen número de encargos y publicaciones para revistas profesionales, empresas (como Publicis, la mayor distribuidora de su tiempo en Francia) y congresos de este sector. Fruto de ese interés surge otro artículo de 1964, profusamente reeditado ${ }^{16}$, titulado "Retórica de la imagen" donde analiza un anuncio gráfico de pasta. Los objetos presentados visualmente (espaguetis, tomates, cebollas, queso parmesano y un champiñón que parecen salir de una bolsa de red) se agrupan en torno a un término léxico, "Panzani", marca del producto que funciona como atractor semántico. La selección de esos productos implica la elección de un campo semántico coherente, ingredientes para elaborar un plato completo de espaguetis, representados únicamente como italianos y por eso diferentes de otros con menos autenticidad y calidad. El eco de la autenticidad cultural se encuentra en el origen del nombre en sí, y en su inflexión y proyección de identidad étnica, sobre todo el mensaje icónico. Puesto que el anuncio está pensado y destinado al consumidor francés, la connotación étnica del nombre y su encaje en una imagen sobreculturizada (aunque presenta exclusivamente ingredientes naturales) reclaman, para Barthes inmediatamente la italianidad como estereotipo turístico. Evocación alimentaria que se convierte inmediatamente en una evocación mítica: el anuncio rebosa estereotipos latentes en la forma de representación y, así, el alimento y su imagen son literalmente inseparables, imagen que no sólo es denotada, sino connotada. La italianización de los productos depende de su situación (que es una relación de enunciación contigua entre la marca Panzani y los productos representados, reforzándose mutuamente y transfiriéndose la connotación del plano léxico al visual y viceversa). Este proceso de transmisión biunívoca de sentido de lo textual a lo visual lo ve Barthes encuadrado en una doble misión de anclaje y relevo: anclaje porque el signo de toda la cadena posible de significantes flotantes nos hace seleccionar los pertinentes (alimento, pasta, productos naturales, marca, italianidad), y relevo porque es capaz de conectar este mensaje con un metalenguaje general, con una cadena sintagmática (la cultura de consumo, la normalidad occidental, el lenguaje del intercambio mercantil) en la que el posible comprador se encuentra reconocido e identificado. En resumen, todo alimento es, pues, una imagen y un texto que lo ancla y lo relaciona con una cultura (que en el capitalismo es una cultura de la mercancía), siempre con connotaciones mitológicas (y, por lo tanto, ideológicas).

\footnotetext{
${ }^{16} \mathrm{La}$ versión definitiva y más accesible se encuentra en Barthes (1992: 29-49).
} 
En $S / Z^{17}$, otro libro escrito a finales de los años 60 , Barthes, antes de pasar a un análisis literario de la obra de Balzac, nos hace una reflexión general que remata el planteamiento de toda su obra anterior. Concluye que, desde la primitiva sociedad capitalista del Renacimiento, se ha venido sustituyendo progresivamente un patrón lingüístico indicial —que se ajustaba a un sistema económico agrícola y que se basaba en el valor de uso (y las relaciones de afinidad directa, la utilidad y las relaciones inmediatas causa-efecto en el seno de una comunidad de sentido-, por un patrón lingüístico simbólico - basado en la sustitución sistemática del objeto por su traducción significante (primero, las cantidades calculables comprables; luego, los atributos traducibles a un patrón común y luego definitivamente las marcas), consecuencia de su adaptación funcional a un mundo dominado por los complejos regímenes del intercambio mercantil. Las leyes de valor de uso se han ido subordinando a las del valor de cambio, y las del valor de cambio a las del valor signo ${ }^{18}$. El sistema alimentario ha realizado la misma transformación y, hoy en día, es imposible separar la alimentación de su representación en la cultura mercantil del consumo.

\section{TEXTO, CUERPO, PLACER. EI hedonismo alimentario}

A principios de los años 70, Barthes madura un cambio de orientación de su obra que le va a encuadrar, según muchos autores, en pleno giro postestructuralista ${ }^{19}$. Fundamentalmente, sus intereses dejan de estar en la constitución de la semiología como crítica de las ideologías (una difícil síntesis entre Saussure y Marx), en la que el intento de desentrañar un significado estable se encuadraba todavía en una

\footnotetext{
${ }^{17}$ En $S / Z$ (Barthes, 2001) se realiza una lectura de una novela breve de Balzac como un texto literalmente desprovisto de autor: se desconecta así la escritura del autor físico (lo contrario al sistema tradicional del comentario de textos positivista).

${ }^{18}$ Es bien conocido que el concepto de valor signo ha sido finalmente difundido por Baudrillard para describir el desarrollo de la forma/mercancía en la forma/signo, como necesaria transfiguración de lo económico en un sistema de signos y del poder económico en una dominación simbólica totalizada (véase Baudrillard, 1974: 55-61). Esta lógica acaba llevando al simulacro al centro de la lógica de las representaciones contemporáneas (Baudrillard, 1984). No olvidemos la filiación directa con Barthes de Baudrillard y que el primer libro de este último se titula El sistema de los objetos (1969), casi la continuación de El sistema de la moda. Si bien el libro del maestro era bastante más sistemático y la evolución de ambos ha tenido sus diferencias, Barthes siempre eligió una cierta estrategia local de reflexividad y retiro; mientras que Baudrillard ha apostado por apuntarse a todos las exhibiciones internacionales.

${ }^{19} \mathrm{El}$ carácter de puente entre un estructuralismo de corte racionalista y un postestructuralismo de orientación deconstructivista que tiene la última parte de la obra de Barthes ha sido constantemente evidenciada, ya sea por autores de ámbito anglosajón -como el crítico y áspero brasileño afincado en Gran Bretaña, Merquior (1989), o el introductorio y muy favorable Trifonas (2004)-, o ya sea por autores franceses - como Descombes (1988) o el muy incisivo Cusset (2003). En todo caso, la aceptación casi unánime de que Barthes formaría parte de esa French Theory que, releida en el ámbito anglosajón, ha constituido la base del movimiento cultural postmoderno, es ya hoy un lugar común.
} 


\section{RIS}

aspiración científica de encontrar una ciencia de los qualia (de las unidades de representación cultural), y en la que era necesario, como petición de principio un sujeto cartesiano para ir constituyendo un conocimiento puro del texto por el texto mismo. El desinterés por el significado se hace evidente ahora y son los efectos de articulación de significantes, como narración, como ficción (aunque tome la apariencia de discurso histórico, científico o descriptivo) o como puro placer, lo que arman la discursividad misma. Barthes empezó cuestionando al autor como unidad biográfica, para luego convertirlo en una especie de malentendido producido por un lector y un conjunto de fragmentos discursivos y mitologizaciones personales; posteriormente, había pensado que la lengua reproducible había suministrado a la ideología su medio más material y más poderoso, y acabó por ampliar a los cinco sentidos la sede de la mistificación ideológica ${ }^{20}$. Ahora se trataría de liberar y abrir todos los sentidos en un proyecto hedonista de amor y reflexión en el que Barthes, mucho más seguro ya en el reconocimiento intelectual de su país - es un autor mundialmente aclamado, obtiene éxitos continuos de ventas, se convierte en miembro del Collège de France, la institución de mayor nivel y prestigio intelectual del país- se interna con decisión. Este período intelectual será el último tramo de su misión creadora.

Las referencias alimentarias en esa época de la obra de Barthes son permanentes, si bien, como es habitual en el Barthes ensayista, no sistemáticas. En El imperio de los signos ${ }^{21}$, su libro sobre Japón (o mejor sobre la imposibilidad de escribir sobre Japón desde un enfoque occidentalista supuestamente descriptivo y neutral) registra todo el poder del ritual (signos vacíos que se pueden narrar, pero que no se pueden interpretar desde el racionalismo habitual de la mirada colonial), un ritual que atrapa todos los sentidos (la escritura es pintura, la comida es teatro, etc.) y que abre la comida al cuerpo en su conjunto (la tradición japonesa prepara la comida delante del comensal, la tendencia a servir pequeñísimos fragmentos cortados refuerza el rito y a la vez la sensualidad, los palillos sólo permiten pequeñísimos y parsimoniosos bocados; el arroz es el único elemento de peso, de síntesis, pero a la vez es ligero y fragmentado, etc.). El placer y el cuerpo como estructuración, la comida y el texto funcionan como principios de goce y ninguno de los dos es ni claramente cultural, ni claramente natural: los intentos de un orden armónico (sea el que sea) impuestos sobre el cuerpo son siempre

\footnotetext{
${ }^{20}$ Véase el análisis que hace Milner (2004) de este proceso en la obra de Barthes, y su diagnóstico del paso de una ciencia de los qualia o una exploración de thesei de la vida moderna.

${ }^{21}$ Sontag (1983) nos recuerda que el interés de Barthes por las formas y los estilos japoneses fue permanente a lo largo de toda su vida y que, desde principios de los años 40 , hay referencias a ello en sus escritos más juveniles, es decir, mucho antes, pues, de El imperio de los signos (edición española de 1991), escrito después de varios viajes a Japón y de un seminario realizado sobre el tema a finales de los años 60 .
} 
fascistas ${ }^{22}$. La idea de un cuerpo natural sin pasar por lo cultural es ilusa (no existe un cuerpo natural, sino una ficción de cuerpo). El hedonismo postmoderno hace así su presencia en la obra de Barthes: ritos, placer, cuerpo, sexo, son palabras claves en el giro postmoderno de nuestra cultura, donde precisamente el renacer de una gastronomía especialmente sobresimbolizada (e individualizada) ha sido una de sus señas de identidad más características.

El texto de Barthes más representativo de ese período, en que se abordan directamente temas alimentarios, es el entusiasta prólogo que, en 1975, le dedica al clásico de los clásicos de la literatura culinaria, esto es, el libro de Jean-Anthelme Brillat-Savarin, Physiologie du goût ${ }^{23}$. Esta obra aparece en 1825, un año antes de la muerte de su autor, con el significativo subtítulo - en relación con la posición del propio Barthes- de Meditación sobre gastronomía transcendente, obra teórica, histórica y a la orden del día . Brillat-Savarin es un hombre de origen aristocrático, exiliado después de la Reyolución, viajero por Estados Unidos, rehabilitado en 1800, cuando ocupa un puesto en el Tribunal Supremo. Prácticamente, inaugura la literatura gastronómica en un doble plano: por una parte, es la perfecta representación de la gastronomía mundana, del gourmet en la ceremonia burguesa de la distinción; por otra, es el origen del análisis organoléctico del gusto, descomponiéndolo en las componentes funcionales de los sentidos, pero también en sus contextos representacionales (la expectación y el ansia del alimento). Es un libro filosófico, aforístico, fisiológico (hay todo un tratado sobre la formación del sabor en las diferentes partes de la lengua y en el conjunto de la cavidad bucal), de anécdotas, de viajes y de pasión hedonista, representante como ninguno del traspaso de los saberes aristocráticos a la moderna burguesía.

Barthes encuentra en Brillat-Savarin un modelo de pansensualismo gastronómico total, que él por su parte se afana en convertir en un pansensualismo textual y simbólico. De esta manera, Barthes recoge la idea del escalonamiento de la experiencia gustativa de Brillat-Savarin, o paso por los momentos del sabor directo (o formado en la lengua), el sabor completo (parte posterior de la boca) y el sabor reflexivo (del juicio en el que se fusiona con otras sensaciones) comparándolos con el tempo de un relato. Por lo tanto, sin posibilidad de narración, no hay auténtica comida. Inmediatamente después aparece lo que llama R. Barthes la gran aventura del deseo, en la que sitúa J. A. Brillat-Savarin la auténtica ali-

\footnotetext{
${ }^{22}$ Véanse las reflexiones, a este respecto, en el muy inquietante texto de Barthes, Sade, Fourier, Loyola (edición española de 1997). Por el contrario, una reivindicación del placer del texto como quien saborea un plato exquisito, se encuentra en Barthes (1974).

${ }^{23}$ Afortunadamente, disponemos de una versión española del libro de Brillat-Savarin (1987). Son muy interesantes las reflexiones de Vázquez-Montalbán (1997) desde su inteligente proyecto de gastronomía política. Korsmeyer (2002) introduce a Brillat-Savarin en las polémicas contemporáneas sobre el gusto, con un conocimiento y dominio académico del tema realmente admirables. $\mathrm{El}$ artículo de Barthes que comentamos se encuentra en Barthes (1999).
} 
mentación. Muy por encima de lo que nuestro clásico llama apetito de necesidad, se despliega el apetito de lujo: el deseo aparece así en toda su fuerza social, es la ceremonia de mostrar (o buscar) el poder. El lustre es así la expresión corporal de ese poder: el goce gustativo se extiende, pues, por todos los sentidos y acaba teniendo efectos corporales externos. Por eso, es una mitología masculina típica representar a las mujeres como cuerpos gloriosos (o como cocineras), pero nunca comiendo, pues esa capacidad digestiva abre una puerta a un poder social que debe ser inmediatamente reprimido en el caso de la mujer. Barthes va siguiendo así, milimétricamente, a un Brillat-Savarin que busca una especie de reducción de lo alimentario a un conjunto de líquidos y jugos alimenticios que acaban abriendo el camino a un placer intenso, siendo el gusto la simple capacidad de discernir lo que agrada (es placentero) de lo que desagrada (produce disgusto, displacer).

Lógicamente, Barthes saca un enorme partido a la polisemia y la multifunción de la lengua (órgano del gusto, órgano de la fonación) y la posibilidad de que la oralidad se despliegue en todos sus niveles, incluso en el de que el deseo tenga que ser nominado, apreciando en Brillat-Savarin su capacidad de crear nuevos términos para relatar el nombre del sabor y de la presentación social de la comida. Barthes remarca las muchas similitudes de Brillat-Savarin con Fourier (que además de ser su cuñado, participaba del mismo espíritu de la época al intentar crear un nuevo mundo de los sentidos, como nuevo mundo social y amoroso que no dejaba de ser la utopía del orden puesto en positivo de la burguesía dominante en ascenso), y en ambos encuentra un sentido global del placer y del cuerpo, del bienestar y del disfrute. La literatura gastronómica de Brillat-Savarin sirve, pues, para ponernos ante un lenguaje deseante directo, ante la memoria de los sentidos, pero también para darle a ese placer una legitimación cientifica, para fundar una ciencia del gusto. Se intuye ya de sobra que el nuevo discurso gastronómico debe fundarse y fundirse en ciencia y placer (pocas cosas de mayor actualidad que esta síntesis). Por fin Barthes se detiene en las referencias de Brillat-Savarin a la socialidad alimentaria, así como en la inseparable unión entre buena comida y acto social, sobre la idea de que todo placer alimentario tiene un componente de convivencialidad: es un placer compuesto y sobredeterminado por una simultaneidad de causas imposibles de diferenciar. El acto social alimentario no es sólo un hecho social que remite a la comunicación como función, sino fundamentalmente a la comunicación como goce; hedonismo que lleva a Brillat-Savarin a huir y rechazar la comida sólo como función y necesidad, atribuyendo a las clases humildes de la época una falta de valores y cultura. Barthes resalta, precisamente, esta ausencia clamorosa en el discurso de los orígenes de la gastronomía burguesa: no existe la comida popular, y cuando se nombra es bajo la especie de lo indeterminado, lo harinoso, lo flatulento, lo pesado, en suma, lo que no tiene discurso, lo que no es ni distinguido ni distinguible.

Por tanto, Barthes se sirve de Brillat-Savarin para presentar la comida como un discurso y como un hecho social total en el que se convocan los metalenguajes más diversos (la fisiología, la geografia, la historia, la economía, hoy la semiología), y 
en el que su llamamiento al gusto (al placer, al goce) no es simplemente una manía, sino un operador universal del discurso. Brillat-Savarin sintetiza el doble viaje de la burguesía de la época hacia el positivismo y hacia el romanticismo, hacia la ciencia y el símbolo, hacia el cálculo y el sensualismo. Parece que está abierto el camino alimentario al goce. Barthes vuelve a reclamar y a revitalizar el proyecto de liberar todos los goces, pero en una clave postburguesa; en ese sentido, sí que está ejerciendo de profeta de una postmodernización cuyas señas de identidad (si es que hablar de identidad en la postmodernidad no es ya un oxímoron) no se pueden encontrar más que en una combinación de la tecnología con el hedonismo. En ese hedonismo, la alimentación ha jugado un papel cardinal.

\section{FRENTE A LOS SÍMBOLOS, LAS PRÁCTICAS. Los infortunios sociológicos} de Roland Barthes

Las lecturas y repercusiones sociológicas de la obra de Barthes han sido muchas y diversas, pero nunca exentas de polémica y controversia. Por una parte, la recepción anglosajona de la primera parte de su obra, sobre todo de las Mitologias, lo convierte en uno de los primeros exportadores de la moda estructuralista, ejerciendo, sobre todo, el papel (por su especial mirada cotidiana) de facilitador de la síntesis entre las versiones menos extremas de ese estructuralismo con los que luego serán considerados como "estudios culturales"24, así como de su directa aplicación a la investigación en el consumo. De la influencia de Barthes sobre la sociología francesa del consumo en su versión postestructuralista es necesario hablar poco, y algo hemos dicho ya: la parte primera de la obra de Baudrillard está escrita en referencia a Barthes, y sería impensable sin su intervención personal y sin su impulso intelectual (con lo que Baudrillard significa para la cultura postmoderna ${ }^{25}$ ). Asimismo, los autores llamados cotidianistas —en versiones más o menos elaboradas de sociologías fenomenológicas y sus síntesis contemporáneas- han acudido muchas veces a Barthes más por su problemática, campo de estudio y soluciones ofrecidas, que por su matriz teórica de origen, que resulta casi antitética (antítesis especialmente visible sobre todo en los temas alimentarios) ${ }^{26}$.

\footnotetext{
${ }^{24}$ Para una revisión general del tema, véase Mattelart y Neveu (2004) y Stirinati (2003). En ambos se resalta el papel de Barthes en la gestación de los estudios culturales y las teorías de la cultura popular. Hasta podemos encontrar reivindicaciones de la obra de Barthes en los estudios de género, en obras como las de Pfenninger (1996).

${ }^{25}$ Para una cartografia del mapa cultural postmoderno y el importante papel que ocupan en él los autores que aquí estamos considerando, véanse Anderson (2000:70-74) y Jameson (1996: 85-97), y como magnífica introducción, Butler (2002), donde se refleja el largo y extenso papel de Barthes y Baudrillard en la recepción anglosajona del movimiento postmodernista.

${ }^{26}$ Véase de manera directa para el tema alimentario el artículo de Maffesoli (2000).
} 
RIS

REVISTA INTERNACIONAL DE SOCIOLOCIA

$\mathrm{N}^{\circ}$ 40, ENERO-ABRIL, 2005

Sin embargo, el choque más directo con las posiciones de Barthes, incluso en su particular visión de lo alimentario, es con la manera de hacer sociología de Bourdieu. La simpatía de Bourdieu por la obra de Barthes es pequeña, y ya de raíz impugna su método, formación y orientación intelectual. Así, el ensayismo, la ausencia de investigación empírica de base realmente social, el lugar confortable (marginal, pero parasitario) en el cerrado y oscuro mundo del mandarinato filosófico francés, son reproches permanentes de Bourdieu a la obra de Barthes, apartándose clara y tajantemente de su proyecto intelectual: "la crítica no de la cultura, sino de sus usos sociales como capital e instrumento de dominación simbólica es incompatible con el divertimento esteticista, aunque recubierto de una forma científica como en el caso de Barthes o de Tel Quel (y no hablemos ya de Baudrillard) que tanto agrada a estos filósofos franceses que han llevado la estetización de la filosofía a un lugar no igualado"27. Pero además de esta negación de la mayor, Bourdieu contrapone directamente su visión de la cultura de consumo a la que se deriva del estructuralismo de matriz lingüística, y en muchos de sus libros la alusión crítica es directa .

En todo caso, la lógica del consumo alimentario que presenta Bourdieu es radicalmente diferente a la de Barthes. De entrada, Bourdieu destierra cualquier autonomía del signo y del código cultural alimentario, para remarcar la dimensión del consumo como práctica y uso social diferencial de los distintos grupos y clases sociales. La identificación absoluta del producto con sus signos, dejando al sujeto como puro decodificador mitologizado, es criticada por Bourdieu, quien propone una relativización del signo y sus funciones lingüísticas (sean mitologizadas, comunicativas o puramente hedonistas) para colocar a estos signos, precisamente, en el sistema de relaciones sociales como elementos prácticos de dominación o contradominación social. Ya no es la cultura, sino el capital simbólico, así como ya no es la estructura lingüística, sino la estructura social, lo que tiene poder explicativo en el campo de las significaciones. La reducción a un sistema de diferencias, oposiciones y composiciones ahistóricas, así como la búsqueda de un código último (sea textual o sensual) es para Bourdieu, además de un ritualismo academicista propio del circuito universitario francés (reiteradamente criticado por este autor a lo largo de toda su obra), la demostración palmaria de la incapacidad

\footnotetext{
${ }^{27}$ La cita es de Bourdieu y Wacquant (1994:132), pero abundan referencias en el mismo sentido en muchísimas obras de Bourdieu que no vamos a detallar. Quizás lo más brutal sea la de la edición de 1992 de su Homo Academicus, donde a Barthes se le acusa de dejarse llevar por el campo intelectual francés, flotando interesadamente a favor de las modas y el relumbrón periodístico, sin tener ninguna contribución (ni obligación) académica real (1992: 298-307). En todo caso, el centro de la sociología del consumo de Bourdieu, una obra ya imprescindible en la evolución de la teoría sociológica, como es La distinción (Bourdieu 1988) y de donde se deriva también su sociología de la alimentación, es una réplica práctica del estructuralismo lingüístico que se encuentra en la base argumentativa de Barthes y Baudrillard.
} 
del estructruralismo para explicar las prácticas concretas de los actores concretos (entendiendo la práctica como el intento de dar sentido y efecto a la acción social), que buscan en sus movimientos (conflictivos por definición) aumentar y/o hacer valer sus capitales (sean económicos, culturales, simbólicos o sociales). Los signos no son sólo interdeterminaciones de un sistema autorreferente, sino relaciones de clase con usos no tanto inconscientes como incorporados (es decir, se materializan en un habitus, en una gramática social generadora de prácticas), que producen y reproducen conflictivamente las diferencias de clase.

El mito y el código en Barthes han absorbido a todos los sujetos, y este metalenguaje - que toma forma de simulacro en las versiones más escandalosas del estructuralismo ${ }^{28}$ - es el depósito de todas las jerarquías y dominaciones. Según Bourdieu, el estructuralismo desconoce todas las razones y los sentidos prácticos de las actividades de los sujetos (empezando por las prácticas alimentarias), para describir solamente una retórica de los signos, las imágenes, los textos y los gustos sin intervención real de los agentes sociales. El gusto en Bourdieu no es un código, es la expresión de una posición social. Los alimentos son para este autor el objeto que revela con más claridad la herencia del mundo familiar, y por ello el gusto gastronómico es una objetivación del gusto de clase que configura y estabiliza el habitus. Los ingresos económicos (pero también el capital cultural, simbólico y social) explican la selección de alimentos, la forma de cocinarlos y las maneras a la mesa. Bourdieu hace - a partir de un ingente material empírico reprocesado - una descripción minuciosísima de las diferentes clases y grupos sociales, resultado de la división social y sexual del trabajo. Se presenta así una versión multidimensional (económica, cultural, política y simbólica) de las diferencias de clase y de sus maneras de comprar, cocinar y servir los alimentos, encontrando regularidades que representan las prácticas alimentarias de los grupos sociales como formas de valoración de sus capitales y como ajustes razonables entre sus recursos y sus objetivos. El anclaje del signo alimentario no está en el lenguaje abstracto, ni en la textura sensual, sino en la lógica que reproduce dinámicamente las diferencias del sentido de consumir para cada grupo social.

Otra visión de la cuestión alimentaria desde el plano fundamental de las prácticas cotidianas es la que proponen Certeau y sus colaboradores, de enorme

\footnotetext{
${ }^{28}$ La desaparición del sujeto práctico hasta convertirlo en máquina simbólica, deseante, clasificatoria o hedonista ha sido uno de los temas centrales del postestructuralismo francés, sea en su radicalización psicoanalítica, filosófica, lingüística o antropológica. En el campo alimentario, tenemos ejemplos como el de Chatelet (1977), lleno de referencias a las "máquinas-boca". Bourdieu se vino manifestando reiteradamente contra este tipo de deriva del estructuralismo hasta el final de su vida, como lo prueba su último socioanálisis del campo intelectual francés en el que él mismo se incluye como referencia: véase Bourdieu (2004).
} 
RIS

repercusión en las ciencias sociales y los estudios culturales actuales ${ }^{29}$. La visión de este autor se aleja tanto del culturalismo abstracto del estructuralismo, asentado en el modelo lingüístico (con ciertos aspectos de Barthes y sobre todo de Lévi-Strauss), como del sociologismo materialista de Bourdieu y su reducción de toda práctica a la posición de clase (por muy multidimensionalmente que esté definida esa clase). Se propone, por tanto, una visión de las prácticas culinarias mucho más cercana al espíritu de los análisis de Bajtin sobre la cultura popular ${ }^{30}$, e incluso del primer Barthes de las Mitologías, que del cientifismo diacrónico de Lévi-Strauss (al que se le reconoce su peso teórico en una visión antropológica de las sociedades sin historia, pero se le reprocha su escasa visión de las prácticas sociales concretas) o del reproductivismo, un tanto mecánico, del trabajo de Bourdieu (que acaba trasponiendo las formas alimentarias a los lugares sociales sin las mediaciones de identidades, creadas por maneras de hacer y formas de socialidad locales y particulares, imposibles de derivar de la posición social macro).

Sin embargo, para Certeau - a partir de un ingente material de observación e investigación etnográfica de la vida cotidiana francesa-, en cada alimento hay un entrecruce de historias invisibles, y cada manera de tomar, preparar y compartir la comida no es sólo una forma pasiva de repetición de códigos, tradiciones o incluso mensajes mediáticos, sino una forma activa y adaptativa de formar sentido y construirlo. Aunque subyugado por la lectura cotidiana de Barthes, el ángulo desde el que ataca Certeau la alimentación no es, pues, el del mito que utiliza a los sujetos, sino la inmensa capacidad de creación y reelaboración particular por parte de materiales y procedimientos no propios por parte de los sujetos concretos de modificar, mediante sus minúsculas estrategias y sus propias "artes de hacer", el sentido y los resultados de sus prácticas culinarias, independientemente del sistema mercantil o de los simples dictámenes mediáticos sobre la alimentación. Certeau concibe así la alimentación como pequeña creación del sentido del

\footnotetext{
${ }^{29}$ La edición definitiva está en Certeau (1990) y los textos específicamente dedicados a la alimentación y la cocina fueron escritos con Luce Girard , que rescató los materiales originales de su maestro (Certeau, Girard y Mayol, 1994: 195-239). En la gran biografia de Dosse (2002) podemos encontrar las detalladas redes de influencia crítica, del estructuralismo francés primero y de la etnometodología anglosajona después, sobre la apasionante obra de M. de Certeau.

${ }^{30}$ Recordemos que M. Bajtin dedica un capitulo de su impresionante libro sobre Rabelais al banquete y a la función subversiva de la comida, en la expresión carnavalesca y en lo pantagruélico de la cultura popular Bajtine (1987: 250-273). Hay que mencionar que Bajtin utiliza constantemente a Michelet (autor de cabecera de R. Barthes) en su obra y que, vía J. Kristeva (discípula fundamental de R. Barthes), se introduce en Francia la obra del propio M. Bajtin, con lo que esto supone para el encuentro posible de las tesis teóricas que aquí se exponen (véase Peytard, 1995). Los testimonios de admiración hacia la obra de Bajtin realizados a lo largo de toda la obra de M. de Certeau son, también, abundantes.
} 
mundo de la vida popular, donde utilizaciones y reutilizaciones, trucos y recetas, asimilación y mezcla de procedimiento acaban por formar no sólo un espacio de seguimiento de normas (sean éstas cuales sean), sino de resistencia y creatividad cotidiana, que le dan la última vuelta de tuerca a cualquier prescripción tecnocrática o mitológica.

Esta atención a la alimentación como desmitificación, cultura popular, hibridación y creatividad irónica subyacente no significa para nada tratar de negar la potencia de todos los poderes establecidos posibles, ni entrar en cualquier deriva populista, sino simplemente subrayar que toda práctica alimentaria se acaba perfilando y toma cuerpo en un ámbito cotidiano no directamente reproductivo, sino situacional, plástico y adaptativo. Por otra parte, esta pretensión no es nueva. Por una vía de reflexiones y entradas teóricas diferentes, pero con resultados similares, el gran historiador de la cultura Gombrich propuso un programa de investigación de la formación del gusto alejada de cualquier determinismo social, antropológico o incluso historicista, reclamando la lógica de las situaciones y la racionalidad limitada y adaptativa de los individuos y sus productos culturales, entre los cuales las formas alimentarias pueden ocupar un lugar esencial ${ }^{31}$.

\section{CONCLUSIONES}

Barthes ha sabido mostrarnos como nadie que todo hecho alimentario, por mínimo que sea, está incrustado en un universo simbólico que tiende a la mitificación. Por ello, ya nunca podremos investigar (e incluso intervenir en) el hecho alimentario, tomado como hecho social total, si no acometemos esta dimensión simbólica, a la vez generadora y distorsionadora, que convierte a la comida en un lenguaje y un relato. Si bien la antropología estructural ha remarcado suficientemente este plano mítico, también es cierto que lo había colocado en un lugar lógico o cognitivo más allá de la historia. Ha sido Barthes quien le ha dado a estas mitologizaciones su carácter cotidiano, concreto e ideológico, como operadores semánticos en la construcción de una idioesfera dinámica, pero anclada sobre reglas recursivas, tan presente en nuestras vidas como el aire que respiramos o el alimento físico que nos sustenta. Barthes, a su vez, fue evolucionando en su concepción del hecho alimentario, pasando del signo al texto y del texto a la textura o, si se quiere, del

\footnotetext{
${ }^{31}$ Son curiosos los paralelismos entre Gombrich (1989) y Certeau en defender la permanente plasticidad y actividad del gusto y la potencia de la lógica de la situación, si bien evidentemente uno afronta el tema desde el individualismo metodológico liberal y el otro desde el imaginario de los grupos sociales concretos.
} 


\section{RIS}

mito al imperio de los signos y de éste al imperio de los sentidos ${ }^{32}$. La producción simbólica de la realidad alimentaria es, por tanto, una dimensión estratégica que Barthes fue componiendo desde el mito, desde el lenguaje y desde el goce. Todas estas dimensiones se han demostrado, además de fundantes y fundamentales en cualquier sociedad humana, especialmente reforzadas en eso que hoy convencionalmente llamamos sociedades postmodernas.

Con su perspicacia característica, Latour ha señalado las grandezas y limitaciones de este giro semiológico que Barthes fue el primero en dar de manera magistral, y en muchos aspectos de manera mucho más razonable que otros intentos más escandalosos ${ }^{33}$. Latour recalca la capacidad de este enfoque de estudiar el discurso como mediador independiente y con autonomía relativa tanto de la naturaleza como de la sociedad. Sin embargo, para él el problema de esta aproximación no es la pérdida del referente realista, ni el olvido de la capacidad creativa del hombre (y mejor del ser humano social) - son las típicas críticas positivas/objetivistas y humanistas modernas-, sino el haber centrado su proyecto únicamente en el discurso, dejando fuera tanto la referencia al mundo natural, por un lado, como la identidad de los sujetos hablantes y pensantes, por otro (cuestiones ambas fundamentales en el tema alimentario). Según Latour ha sido fundamental esta labor de descubrimiento de los sistemas articulados de signos en la creación de los estudios de los procesos de traducción de lo natural a lo social y de lo social a lo natural. Sin embargo, no se puede hacer a costa de aislar lo natural y lo social y darle a lo textual la función de relato autoportante y generativo. En la visión de Latour hay una propuesta de hibridación entre lo natural, lo social y lo discursivo, tanto en el plano analítico como en el plano constructivo. Ello rompe con cualquier pretensión de imperialismo científico, sociológico o lingüístico.

Esta condición de hibrido es especialmente relevante en la alimentación contemporánea. Lejos de cualquier simplificación más o menos espectacular (por una parte, comida basura, plástico y McDonalización o, por otra, nueva cocina, cocina del terreno, neotradición, etc.), sabemos que nuestro actual proceso de alimentación - como todo sistema emergente ${ }^{34}$ - está construido por elementos naturales, tecnológicos, simbólicos y sociales muy complejos, que se mezclan en

\footnotetext{
${ }^{32}$ Definía R. Barthes en sus últimos cursos en el Collège de France (1977-1978), hoy felizmente rescatados, que las ideosferas son los sistemas discursivos fuertes que imponen las ideologías, creando los entornos lingüísticos legítimos. R. Barthes reflejó en muchos de sus escritos esta idea de que respiramos ideología como respiramos aire y, por lo tanto, nuestros medios lingüísticos nos suministran nociones de poder sólo por estar en ellos. No nos movemos así en ambientes comunicativos neutros y naturales (véase Barthes, 2002: 123 y ss).

${ }^{33}$ Las dos referencias clásicas de B. Latour siguen siendo fundamentales en este campo (véase Latour, 1992 y 1993).

${ }^{34}$ Para la noción de sistema emergente, como conjunto de elementos simples que se organizan sin leyes explícitas hasta dar lugar a un comportamiento adaptado, ver Johnson (2004).
} 
síntesis y superposiciones concretas (exótico y cotidiano, innovación y seguridad alimentaria, industrialización y familia, grandes series y nueva diferenciación, global y local, etc.). Discursos muy mitologizados (llenos de connotaciones y naturalizaciones) se nos presentan como si todas sus prescripciones formasen parte de nuestra condición de occidentales opulentos (el de la alimentación como fuente de vigor y salud, el del goce social, el de la recuperación de lo natural, el de lo tradicional regional y un larguísimo etcétera), lo que acaba formando también una nueva condición gastronómica ecléctica, fragmentada, desigual y postmoderna con fuertes tendencias anómicas. Gastronomía y gastro-anomia, presiones y tendencias tan diferentes se acaban resolviendo en una desintegración normativa creciente, expresión de una sociedad con más libertades y posibilidades, pero también con más riesgos y con comportamientos alimentarios potenciales aberrantes ${ }^{35}$. Nuevos mitos y ritos surcan nuestro imaginario colectivo alimentario, y el mito - nos lo enseñó Barthes-mezcla la memoria, aculta la producción, naturaliza lo social, inventa tradiciones, propone determinismos históricos. Gran parte de nuestra responsabilidad social actual está en analizarlos, deconstruirlos, reconstruirlos y conocer su poder en la creación de las buenas (y malas) prácticas alimentarias.

En el admirable trabajo de Poulain, abundantemente utilizado en estas páginas, se acaba reclamando y revitalizando un concepto clave: el de espacio social alimentario ${ }^{36}$. Con él, además de tratar de acabar con las falsas dicotomías que tanto daño han hecho a la concepción de la alimentación como un hecho intrínsecamente multidimensional (material/cultural, sincrónico/diacrónico, producción/consumo, progreso/pérdida de calidad, tecnológico/natural, etc.), se perfila la necesidad de concebir las prácticas alimentarias como constructos compuestos en todas las dimensiones en que se constituye lo social mismo; con sus ambivalencias y sus contradicciones, pero también con la potencia de que son prácticas incorporadas: son el puente más directo entre el cuerpo individual y el cuerpo social. En suma, el ser humano no se alimenta sólo de nutrientes (proteínas, vitaminas, minerales, grasas o cualquier otra sustancia), sino de comida producida y consumida según todo tipo de procedimientos económicos y sociales, que además condensan sentido diferencial y se reproducen en un horizonte de símbolos, signos y mitos ${ }^{37}$.

\footnotetext{
${ }^{35}$ Es la tesis central de Fischler (1995).

${ }^{36}$ Poulain (2002: 221-244) indica en su libro la intensa y compleja trayectoria de este concepto. Otro gran sociólogo de la alimentación francés, Grignon (por ejemplo, 1987), utiliza también este concepto, si bien operativizado de una manera más analítica. Las magníficas reflexiones de Grignon y Passeron (1992) ante la obra de Bourdieu son también de enorme utilidad para el análisis del hecho alimentario.

${ }^{37}$ Frente al reduccionismo de deducir mecánicamente los modos de alimentación a partir de las necesidades biológicas de la especie y de las adaptaciones materialistas al contexto de un $\mathrm{M}$. Harris (1989) -que da la vuelta a las tesis de C. Lévi-Strauss, sin ni siquiera referirse concretamente a ninguna de sus obras. Assouly (2004) desarrolla una argumentación multidimensional (local/global, simbólica, material) sobre la hibridación alimentaria actual que anticipa, pensamos, una vía fecunda de investigación para los próximos años.
} 
Barthes ha abierto como nadie el estudio de esta dimensión semiológica de la comida, dimensión que deberá combinarse con el resto de los vectores del espacio social alimentario, en un proyecto de estudio interdisciplinario y totalizador de la nutrición humana, que se hace cada vez más imprescindible.

\section{REFERENCIAS BIBLIOGRÁFICAS}

ALDRIDGE, A. (2003), Consumption, Cambridge, Polity Press.

ANDERSON, P. (2000), Los orígenes de la postmodernidad, Barcelona, Anagrama.

ASSOULY, O. (2004), Les nourritures nostalgiques, París, Actes Sud.

BACHELARD, G. (1978), El agua y los sueños. Ensayo sobre la imaginación de la materia, México, Fondo de Cultura Económica.

BAJTIN, M. (1987), La Cultura popular en la Edad Media y el Renacimiento, Madrid, Alianza.

BARTHES, R. (1961), "Pour une phycho-sociologie de l'alimentation contemporaine", Annales, Économies, Sociétés, Civilisations, $\mathrm{n}^{\circ}$ 5, pp. 977-986.

(1971), Elementos de semiología, Madrid, Alberto Corazón/Comunicación.

(1973), El grado cero de escritura, México, Siglo XXI.

(1974), El placer del texto, México, Siglo XXI.

(1978), Roland Barthes por Roland Barthes, Barcelona, Kairós.

(1980), Mitologias, Madrid, Siglo XXI.

(1981), Critique et vérite, París, Seuil/Points.

(1983), Ensayos criticos, Barcelona, Seix Barral.

(1990), "La cocina del sentido", en La aventura semiológica, Barcelona, Paidós.

(1991), El imperio de los signos, Barcelona, Mondadori.

(1992), "Retórica de la imagen", en Lo obvio y lo obtuso. Imágenes, gestos, voces, Barcelona, Paidós.

(1997), Sade, Fourier, Loyola, Madrid, Cátedra.

(1999), "Lectura de Brillat-Savarin", en El susurro del lenguaje. Más allá de la palabra y la escritura, Barcelona, Paidós. 
(2001), S/Z, Madrid, Siglo XXI.

(2002), Le Neutre. Cours au Collège de France (1977-1978), París, Seuil.

(2004), El sistema de la moda y otros escritos, Barcelona, Paidós.

BAUDRILLARD, J. (1969), El sistema de los objetos, México, Siglo XX.

(1974), Crítica de la economía política del signo, México, Siglo XXI.

(1984), Cultura y simulacro, Barcelona, Kairós.

BOURDIEU, P. (1988), La distinción. Criterio y bases sociales del gusto, Madrid, Taurus

(1992), Homo Academicus, París, Minuit.

(2004), Esquisse pour une auto-analyse, París, Raisons d' Agir.

BOURDIEU, P. y L.WACQUANT (1994), Per a una sociologia reflexiva, Barcelona, Herder.

BRILLAT-SAVARIN, J.A. (1987), Fisiología del gusto o meditaciones de gastronomia trascendente Madrid, Aguilar.

BUTLER, Ch. (2002), Postmodernism, Oxford, Oxford University Press.

CALVET, L.J. (1992), Roland Barthes. Una biografia, Barcelona, Gedisa.

CALVINO, I. (1998), "En memoria de Roland Barthes", en Colección de arena, Madrid, Siruela.

COBAST, E. (2002), Mythologies de R. Barthes. Premières leçons, París, Presses Universitaires de France.

COUNIHAN, C.M. y P. van ESTERIK (Eds.) (1997), Food and culture. A Reader, Nueva York, Routledge.

CERTEAU, M. de (1990), L'invention du quotidien 1. Arts de faire, París, Gallimard/Folio.

CERTEAU, M. de, L. GIRARD y P.MAYOL (1994), L'invention du quotidien 2. Habiter, Cuisiner, París, Gallimard/Folio.

CRIGNON, C. y J.C. PASSERON (1992), Lo culto y lo popular, Madrid, La Piqueta.

CULLER, J. (1987), Barthes, México, Fondo de Cultura Económica.

CUSSET, F. (2003), French Theory, París, La Découverte.

CHATELET, N. (1977), Le corps à corps culinaire, París, Seuil.

CHAZAUD, A.S. (2003). "Roland Barthes au la traversée des signes", Bulletin BPI. Bibliothèque Centre Pompidou, enero-marzo, pp. 16-26. 
DESCOMBES, V. (1988), Lo mismo y lo otro. Cuarenta y cinco años de filosofia francesa, Madrid, Cátedra.

DIAZ MÉNDEZ, C. y C. GÓMEZ BENITO (2001), "Del consumo alimentario a la sociología de la alimentación", Distribución y Consumo, noviembre-diciembre, pp 5-23.

DOSSE, F. (2002), Michel de Certeau. La marcheur blessé, París, La Découverte.

(2004), Historia del estructuralismo, akal, Madrid.

DOUGLAS, M. (1998), Estilos de pensar, Barcelona, Gedisa.

ECO, U. (1995), Apocalipticos e integrados, Lumen/Tusquets.

ÉVRARD, F. y E. TENET (1994), Roland Barthes, París, Bertrand Lacoste.

FISCHLER, C. (1995), El (h)omnivoro. El gusto, la cocina y el cuerpo, Barcelona, Anagrama.

FRANÇOIS-DENÈVE, C. (2002), Mythologies, París, Bréal.

GOMBRICH, E.H. (1989), In Search of Cultural History, Oxford, Oxford University Press.

GOODY, J. (1995), Cocina, cuisine y clase, Barcelona, Gedisa.

GREIMAS, A.J. y J. COURTÉS (1992), Semiótica, Madrid, Gredos.

GRIGNON, C. (1987), "L'alimentation des étudiants", Paris, INRA.

GRIGNON, C. y J.C. PASSERON (1992), Lo culto y lo popular, Madrid, La Piqueta.

GUIRAUD, P. (1972), La semiología, México, Siglo XXI.

HARRIS, M. (1989), Bueno para comer, Madrid, Alianza.

HELLER, A. y F. FEHÉR (1995), Biopolitica. La modernidad y la liberación del cuerpo, Barcelona, Península.

HJELMSLEV, L. (1974), Prolegómenos a una teoría del lenguaje, Madrid, Gredos.

JAMESON, F. (1996), Teoria de la postmodernidad, Madrid, Trotta.

JESSI, F. (1976), Mito, Barcelona, Labor.

JOHNSON, S. (2003), Sistemas emergentes, México y Madrid, Turner/Fondo de Cultura Económica.

KORSMEYER, C. (2002), El sentido del gusto. Comida, estética y filosofia, Barcelona, Paidós.

LATOUR, B. (1992), Ciencia en acción, Barcelona, Labor.

(1993), Nunca hemos sido modernos, Madrid, Debate.

106 
LEEDS-HURWITZ, W. (1993), Semiotics and Communication: Signs, Codes, Cultures, Hillsdale, Lawrence Erlbaum.

LÉVI-STRAUSS, C. (1968), Mitológicas I: Lo crudo y lo cocido, México, Fondo de Cultura Económico. (1971), Mitológicas II: De la miel a las cenizas, México, Fondo de Cultura Económica. (1974), Mitológicas III: El origen de las maneras a la mesa, México, Siglo XXI.

(1981), Mitológicas IV: El hombre desnudo, México, Siglo XXI.

(1987), Mito y significado, Madrid, Alianza.

MAFFESOLI, M. (2000), “Table. Lieu de communication”, en Sociétés Vol. 6, pp.12-20.

MARTINET, J. (1988), Claves para la semiologia, Madrid, Gredos.

MATTELART, A. y M. MATTELART (1997), Historia de las teorias de la comunicación, Barcelona, Paidós.

MATTELART, A. y E. NEVEU, (2004), Introducción a los estudios culturales, Barcelona, Paidós.

MERQUIOR, J.G. (1989), De Praga a Paris. Crítica del pensamiento estructuralista y postestructuralista, México, Fondo de Cultura Económica.

MILNER, J.C. (2004), El paso filosófico de Roland Barthes, Buenos Aires, Amorrortu.

MOUNIN, G. (1972), Introducción a la semiologia, Barcelona, Anagrama.

(1987), Clefs pour la linguistique, París, Seghers.

PEYTARD, J. (1995), Mikhail Bakhtine. Dialogisme et analyse du discours, Paris, Bertrand Lacoste.

PFENNINGER, A. (1996), "Food in the Writings of Roland Barthes", Women's and Gender Studies Newsletter, octubre, 29-31.

POULAIN, J.P. (2002), Sociologies de l'alimentation, París, Presses Universitaires de France.

SIMMEL, G. (1988), El individuo y la libertad. Ensayos de crítica de la cultura, Barcelona, Península.

SONTAG, S. (1983), "La escritura misma sobre Roland Barthes", epilogo a BARTHES (1983).

STRINATI, D. (2003), Introduction to Theories of Popular Culture, Londres, Routledge.

TRIFONAS, P.P. (2004), Barthes y el imperio de los signos, Barcelona, Gedisa.

VÁZQUEZ MONTALBÁN, M. (1997), Contra los gourmets, Barcelona, Mondadori.

WUNENBURGER, J.J. (2003), "Figures de la dialectique", en J.J. WUNENBURGER, (Ed.), Bachelard et l'epistemologie francaise, París, Presses Universitaires France, pp. 29-51. 